\title{
Nova gestão da Sociedade Brasileira de Atividade Física e Saúde: o enfrentamento da crise e os novos desafios para a área de atividade física e saúde
}

\author{
Alex Antonio Florindo, Mauro Virgílio Gomes de Barros, Mathias Roberto Loch, Carla Meneses Hardman, Christianne de \\ Faria Coellho Ravagnani, Inácio Crochemore Mohnsam da Silva, Gregore Iven Mielke
}

O Brasil está passando por uma grave crise política e econômica, gerando grande desestabilidade e deixando muitas incertezas sobre o futuro. Neste contexto, estão ocorrendo cortes de verbas em áreas essenciais relacionadas ao fomento da saúde, educação, ciência e tecnologia, entre outras. Esta situação complexa deverá ser enfrentada por toda a sociedade. Teremos que ser fortes, perseverantes, criativos e com a esperança de que os períodos de crise sirvam de alguma forma para o crescimento. A nova gestão da Sociedade Brasileira de Atividade Física e Saúde (SBAFS) formada pelo professor Mauro Virgílio Gomes de Barros (presidente), Alex Antonio Florindo (vice-presidente), Mathias Roberto Loch (diretor científico), Carla Meneses Hardman ( $1^{\mathrm{a}}$ secretária), Christianne de Faria Coellho Ravagnani $\left(2^{\mathrm{a}}\right.$ secretária), Inácio Crochemore Mohnsam da Silva ( $1^{\circ}$ tesoureiro) e Gregore Iven Mielke ( $2^{\circ}$ tesoureiro) vêm, apesar do contexto não favorável e que talvez impeça ou dificulte algumas ações, com a confiança de que muitas coisas boas acontecerão nesta gestão. Essa esperança vem do reconhecimento da evolução do caminho traçado até aqui e principalmente da melhor compreensão dos erros e acertos da SBAFS, que completará 10 anos em 2017. Neste período a SBAFS teve quatro gestões que organizaram, junto com as comissões das respectivas cidades e Universidades, quatro Congressos Brasileiros de Atividade Física e Saúde (Florianópolis, 2009; Gramado, 2011; Curitiba, 2013; São Luís, 2015). Os encontros regionais começaram a ocorrer a partir de 2014, sendo realizados nas cinco regiões do país. Este período inclui também uma participação ativa na organização do Congresso Internacional de Atividade Física e Saúde Pública no ano de 2014 junto com Sociedade Internacional de Atividade Física e Saúde. Este Congresso foi realizado no Rio de Janeiro e foi um grande desafio alcançado pela SBAFS. Assim, um dos novos desafios para esta nova gestão é manter os eventos regionais em 2016 e trabalhar fortemente para celebrar os 10 anos de atividades da SBAFS no Congresso Brasileiro de Atividade Física e Saúde, que será realizado em 2017 na cidade de Florianópolis. Outro grande desafio da SBAFS é colaborar para manter o bom nível da Revista Brasileira de Atividade Física e Saúde (RBAFS). Liderada atualmente pelos editores científicos José Cazuza de Farias Júnior, Airton José Rombaldi e Cassiano Ricardo Rech, a RBAFS teve um expressivo crescimento em quantidade e qualidade 
nos últimos nove anos. Para tanto, o trabalho dos editores associados, pareceristas e a confiança dos autores foi fundamental. Vale lembrar que quando a SBAFS assumiu a RBAFS no ano de 2007 para 2008, haviam números atrasados que foram colocados em ordem. Eram três números por ano, passou-se para quatro números em 2010 e para seis números a partir de 2012. Artigos em inglês passaram a ser aceitos a partir de 2012 e a revista começou a oferecer a opção de tradução dos artigos. Obteve-se financiamento federal para custear a RBAFS durante o ano de 2012 e no ano de 2013 adotou-se a plataforma eletrônica com acesso livre aos artigos publicados. Existem grandes desafios para os próximos anos para a RBAFS. O primeiro é manter o fluxo de seis números por ano, o que não é fácil na área de atividade física e saúde. Depois, modernizar a plataforma eletrônica e internacionalizar a revista, tentando uma maior aproximação com outros países da América Latina e de língua inglesa. Indexar a revista nas bases de dados Scielo e Pubmed/ Medline também é um grande desafio para a RBAFS e a SBAFS pretende apoiar diretamente esta ação. Um último desafio é fazer com que a SBAFS contribua mais diretamente com a formação profissional e com as políticas de promoção da saúde e de atividade física no Brasil. Avançamos na formação de pesquisadores, sendo que a SBAFS já realizou três cursos de formação de pesquisadores (doutores e doutorandos) na área de atividade física e saúde (Curitiba, 2013; Porto de Galinhas, 2014; Gramado, 2015), mas, precisamos avançar com contribuições efetivas para formação de pessoas que atuam profissionalmente com intervenções de promoção da atividade física, como por exemplo, profissionais do Sistema Único de Saúde e professores que atuam no âmbito das escolas com crianças e adolescentes. Precisamos também melhorar a nossa participação política, iniciando discussões que podem contribuir para a promoção da atividade física. Um grande avanço, por exemplo, seria a SBAFS fomentar a discussão de um Guia de Promoção da Atividade Física para o Brasil, o qual pode ser um instrumento político importante para ações intersetoriais e interdisciplinares. Esta gestão pretende ser forte e trabalhar duro para avançar e contribuir com a área de atividade física e saúde. Mas, o caminho futuro desta área no Brasil não depende somente da SBAFS. O enfrentamento dos problemas e a conquista dos desafios depende de toda a comunidade da área de atividade física e saúde, incluindo profissionais, gestores, jovens pesquisadores formados recentemente, pesquisadores mais antigos e experimentes, alunos de graduação e de pós-graduação, bem como toda a população que usufrui e acredita que podemos ter uma vida melhor também por meio da prática de atividade física.

\section{Agradecimentos}

A gestão 2016-2017 da SBAFS agradece aos editores-chefes da RBAFS professores José Cazuza de Farias Júnior, Airton José Rombaldi e Cassiano Ricardo Rech, pela revisão e sugestões referentes à RBAFS. 